\title{
Associations Between Depressive Symptoms, Anxiety Disorders, Their Comorbidity and Health- related Quality of Life: a Large-scale Cross-sectional Study
}

\author{
Wei Liao \\ Zhengzhou University \\ Zhicheng Luo \\ Zhengzhou University \\ Xiaokang Dong \\ Zhengzhou University \\ Xueyan Wu \\ Zhengzhou University \\ Yongxia Mei \\ Zhengzhou University \\ Ningning Cui \\ Zhengzhou University \\ Ning Kang \\ Zhengzhou University \\ Yali Lan \\ Zhengzhou University \\ Xiaotian Liu \\ Zhengzhou University \\ Wenqian Huo \\ Zhengzhou University \\ Fang Wang \\ Shanxi Medical University \\ Chongjian Wang ( $\nabla$ tjwcj2005@126.com ) \\ Zhengzhou University
}

\section{Research Article}

Keywords: Depressive symptoms, anxiety disorders, comorbidity, HRQoL, EQ-5D-5L, rural area

Posted Date: April 19th, 2021 
DOI: https://doi.org/10.21203/rs.3.rs-400533/v1

License: (c) (1) This work is licensed under a Creative Commons Attribution 4.0 International License. Read Full License 


\section{Abstract}

Background: There were few studies exploring the associations between depressive symptoms, anxiety disorders and health-related quality of life (HRQoL) in the general population, especially in resource limited area. The aims of this study were to assess the associations between depressive symptoms, anxiety disorders, their comorbidity and HRQoL in rural area.

Methods: A total of 23496 eligible participants from Henan rural cohort were included. The Patient Health Questionnaire-2 (PHQ-2) and Generalized Anxiety Disorder-2 (GAD-2) were employed to assess depressive symptoms and anxiety disorders, respectively. HRQoL was measured via European Quality of Life Five Dimension Five Level Scale (EQ-5D-5L). Tobit regression and generalized linear model were utilized to explore the associations between depressive symptoms, anxiety disorders, their comorbidity and HRQoL.

Results: A total of 1320 individuals were identified as depressive symptoms with a prevalence of $5.62 \%$, while 1198 participants were classified as anxiety disorders with a prevalence of $5.10 \%$. After multiple adjustment, the regression coefficients and $95 \%$ confidence interval $(\mathrm{Cl})$ of utility index for depressive symptoms and anxiety disorders were $-0.166(-0.182,-0.149)$ and $-0.132(-0.149,-0.114)$, respectively. The regression coefficients and $95 \% \mathrm{Cl}$ of VAS score for depressive symptoms and anxiety disorders were $-7.65(-8.60,-6.70)$ and $-5.79(-6.78,-4.80)$, respectively. Additionally, the comorbidity was strongest associated with low utility index and VAS score. These findings were observed robustly in men and women.

Conclusion: Depressive symptoms, anxiety disorders and their comorbidity were negatively associated with HRQoL in rural population, which needed further efforts on preventive and treatment interventions.

Clinical Trial Registration: The Henan Rural Cohort Study has been registered at Chinese Clinical Trial Register (Registration number: ChiCTR-O0C-15006699). Date of registration: 06 July, 2015. http://www.chictr.org.cn/showproj.aspx?proj=11375

\section{Background}

Mental disorders were major world-wide health problems, which account for $13 \%$ of the global disease burden, and major depression alone was expected to be the largest contributor by 2030 [1]. In China, the prevalence of mental disorders was increasing rapidly, and nearly one in six suffered from mental disorders from 2001 to 2005 [2]. Depression and anxiety were the most prevalent of the many mental disorders, and they often occur together [3]. Our previous study has shown that the age-standardized prevalence of depressive symptoms and anxiety in Chinese rural adults were $5.41 \%$ and $4.94 \%$, respectively [4]. In addition, previous studies indicated that depression and anxiety were negatively associated with a variety of chronic diseases, such as hypertension, type 2 diabetes mellitus (T2DM), and coronary heart disease (CHD) [5-7]. 
Health related quality of life (HRQoL) was a multidimensional concept contented by physical health status and subjective satisfaction with health, which was a reliable indicator to assess health status [8]. Most previous studies have focused on the effect of physical diseases on HRQoL [9-11], but ignored the effect of mental disorders. Previous studies have explored the association between depression, anxiety and HRQoL in specific population [12-14], which indicated that depression and anxiety were negatively associated with HRQoL. However, there were few studies investigating the association in the general population, especially in rural population with limited resources. Additionally, multiple studies have documented that women had higher prevalence and were approximately twice as likely to suffer from depression and anxiety as men $[15,16]$. Thus, it is important to assess gender specific associations between depression, anxiety and HRQoL.

The aims of this study were to explore the associations between depressive symptoms, anxiety disorders, their comorbidity and HRQoL in rural population. In addition, the difference between men and women was assessed.

\section{Methods}

\section{Study population}

The current study, designed as a cross-sectional study, was embedded in Henan rural cohort study, which was a population-based study with a large sample of rural people living in Yuzhou, Suiping, Tongxu, Xinxiang and Yima counties of Henan province in China. From July 2015 to September 2017, 39259 participants aged from $18 \sim 79$ were included in the cohort study via multistage stratified cluster sampling method, with a response rate of $93.7 \%$. Detailed information of the cohort has been described previous publish [17].

Participants were excluded from the study if they had any of the following: (1) Did not participate in the EQ-5D-5L questionnaire survey ( $n=15700)$; (2) Missing EQ-5D-5L data $(n=49)$; (3) Missing depressive symptoms and anxiety data $(n=14)$. Finally, a total of 23496 participants were included in this study.

The Henan Rural Cohort Study was approved by the Zhengzhou University Life Science Ethics Committee and conducted in accordance with the principles of the Declaration of Helsinki (Code: [2015] MEC (S128)). Before the study commenced, participants were informed of the study's purpose, health benefits, and potential hazards. Participants were required to provide informed consent and both the researchers and respondents agreed to use the data for scientific research purposes only.

\section{Data collection}

All participants were interviewed face-to-face by well-trained research staff via a standard questionnaire to collect data including information on demographic characteristics, lifestyle factors and individual history of chronic diseases. To ensure the accuracy and integrity of the collected data, trained investigators checked the integrity and logical errors of the questionnaire on the same day of 
questionnaire completion, and if there were any problems, they contacted the participants by phone and amended the responses.

Demographic covariates included gender, age, marital status, educational level, and average monthly income. Education level was divided into three levels: elementary school or below, junior high school, and senior high school or above. Average monthly income was also classified into three levels: $<500 \mathrm{RMB}$, 500-999 RMB and $\geq 1000$ RMB. Lifestyle factors covered smoking (never, former, and current), alcohol drinking (never, former, and current) and physical activity. The definition of current smoking and current drinking have been described previous publish [18]. Physical activity was grouped into three levels (low, moderate, and high) according to the validated Chinese version of the International Physical Activity Questionnaire (IPAQ) [19]. Chronic diseases which included hypertension, dyslipidemia, T2DM, CHD and stroke were collected via physical examination, laboratory tests, or self-reports [20]. Body height and weight of the participants were measured twice with shoes and coats off and the readings were recorded to the nearest $0.1 \mathrm{~cm}$ and $0.1 \mathrm{~kg}$, respectively. The average readings of the two measurements were taken for statistical analysis in this study. Body mass index $\left(\mathrm{BMI}, \mathrm{kg} / \mathrm{m}^{2}\right)$ was calculated as weight $(\mathrm{kg})$ divided the square of height $(\mathrm{m})$.

\section{Definition of depressive symptoms and anxiety disorders}

In this study, the Patient Health Questionnaire-2 (PHQ-2) and Generalized Anxiety Disorder-2 (GAD-2) were performed to assess depressive symptoms and anxiety disorders. The PHQ-2 and GAD-2 are an abbreviated version of the Patient Health Questionnaire-9 (PHQ-9) and the seven-item generalized anxiety disorder scale (GAD-7), met the demands of busy primary care practice and large population-based surveys. Both two scales were a reliable and valid screening tool for depressive symptoms and anxiety disorders in Chinese rural population [21, 22].

Both two scales were consisted of two items and each item was consisted of four levels (not at all $=0$, several days $=1$, more than half the days $=2$, and nearly every day $=3$ ), with a total score ranged from 0 to 6 . In this study, a cutoff of 3 was adopted to identify depressive symptoms and anxiety disorders [22, 23]. In other words, participants who reported a score of 3 or above for PHQ-2 or GAD-2 scales were classified as having depressive symptoms or anxiety disorders, respectively.

\section{Assessment of HRQoL}

In this study, HRQoL was assessed by European Quality of Life Five Dimension Five Level Scale (EQ-5D$5 \mathrm{~L}$ ), a standardized measure of HRQoL developed by the EuroQol Group in order to provide a simple, generic measure of health for clinical and economic appraisal [24]. The five dimensions of EQ-5D-5L were mobility (MO), self-care (SC), usual activities (UA), pain/discomfort (PD) and anxiety/depression (AD) and each dimension was consisted of five levels (no problems, slight problems, moderate problems, severe problems, and extreme problems). The EQ-5D-5L utility index was calculated according to the recently available Chinese value set for the EQ-5D-5L instrument [25]. The calculated formula of EQ-5D-5L utility index can see in elsewhere [26]. The EQ-5D-5L also included a visual analogue scale (VAS), a vertical 0 to 
100 point rating scale, which reflects the degree of satisfaction with their health status. The best and worst health states carry a score of 100 and 0, respectively.

\section{Statistical analysis}

Statistical description was presented as frequencies and percentages for categorical variables, while means and standard deviations (SD) were calculated for continuous variables. T-test or Kruskal-Wallis test was performed to compare differences between different groups for continuous variables, while Chi squared test was utilized for categorical variables.

Multivariate Tobit regression model [27] was performed to explore the associations between depressive symptoms, anxiety disorders and utility index, due to the distribution of the EQ-5D utility was skewed and the utility index was censored at 1. Due to the VAS score was abnormal distribution, a generalized linear model (GLM) was employed to assess the associations between depressive symptoms, anxiety disorders and VAS score. Model 1 was unadjusted. Model 2 adjusted age, gender, marital status, education level, average monthly income, physical activity, smoking status, drinking status, and BMI. Model 3 further adjusted hypertension, dyslipidemia, T2DM, CHD and stroke based on model 2.

Data were analyzed using SPSS 23.0 software package (SPSS Institute, Chicago) and STATA 15 for Windows. All $P$ values were two-tailed with a statistical significance level of 0.05 .

\section{Results}

\section{Characteristics of study participants}

Characteristics of study participants according to depressive symptoms and anxiety disorders were presented in Table 1. A total of 1320 individuals were identified as depressive symptoms with a prevalence of $5.62 \%$, while 1198 participants were classified as anxiety disorders with a prevalence of $5.10 \%$. The mean age \pm SD of participants (41.59\% male and $59.41 \%$ female) was $55.28 \pm 12.63$. Compared with non-depressive group and non-anxiety group, depressive group and anxiety group were more prone to older, women, low education level, and low average monthly income, and less likely to be married/cohabiting, current smoking, current drinking, and obesity (all $P<0.05$ ). The mean (SD) utility index and VAS score of the total sample were 0.954 (0.111) and 78.33 (14.80), respectively. Participants with depressive symptoms or anxiety disorders had lower utility index and VAS score than these without depressive symptoms or anxiety (all $P<0.001$ ). 
Table 1

Characteristics of study participants according to depressive symptoms and anxiety disorders.

\begin{tabular}{|c|c|c|c|c|c|c|c|}
\hline \multirow[t]{2}{*}{ Variable } & \multirow{2}{*}{$\begin{array}{l}\text { Total } \\
(n= \\
23496)\end{array}$} & \multicolumn{2}{|c|}{ Depressive symptoms } & \multirow[t]{2}{*}{$P$} & \multicolumn{2}{|c|}{ Anxiety disorder } & \multirow[t]{2}{*}{$P$} \\
\hline & & $\begin{array}{l}\text { Depressive } \\
(n=1320)\end{array}$ & $\begin{array}{l}\text { Non- } \\
\text { depressive } \\
(n=22176)\end{array}$ & & $\begin{array}{l}\text { Anxiety } \\
(n= \\
1198)\end{array}$ & $\begin{array}{l}\text { Non- } \\
\text { anxiety } \\
(n= \\
22298)\end{array}$ & \\
\hline $\begin{array}{l}\text { Age (year, mean } \pm \\
\text { SD) }\end{array}$ & $\begin{array}{l}55.28 \\
\pm 12.63\end{array}$ & $\begin{array}{l}56.40 \pm \\
12.33\end{array}$ & $\begin{array}{l}55.22 \pm \\
12.64\end{array}$ & 0.001 & $\begin{array}{l}56.16 \\
\pm 11.81\end{array}$ & $\begin{array}{l}55.24 \pm \\
12.67\end{array}$ & 0.009 \\
\hline Women n (\%) & $\begin{array}{l}13959 \\
(59.41)\end{array}$ & $\begin{array}{l}886 \\
(67.12)\end{array}$ & $\begin{array}{l}13073 \\
(58.95)\end{array}$ & $<.001$ & $\begin{array}{l}842 \\
(70.28)\end{array}$ & $\begin{array}{l}13117 \\
(58.83)\end{array}$ & $\begin{array}{l}< \\
0.001\end{array}$ \\
\hline \multicolumn{8}{|l|}{$\begin{array}{l}\text { Educational level } \mathrm{n} \\
(\%)\end{array}$} \\
\hline $\begin{array}{l}\text { Elementary school } \\
\text { or below }\end{array}$ & $\begin{array}{l}10110 \\
(43.03)\end{array}$ & $\begin{array}{l}682 \\
(51.67)\end{array}$ & $\begin{array}{l}9428 \\
(42.51)\end{array}$ & $<.001$ & $\begin{array}{l}635 \\
(53.01)\end{array}$ & $\begin{array}{l}9475 \\
(42.49)\end{array}$ & $<.001$ \\
\hline Junior high school & $\begin{array}{l}8979 \\
(38.22)\end{array}$ & $\begin{array}{l}459 \\
(34.77)\end{array}$ & $\begin{array}{l}8520 \\
(38.42)\end{array}$ & & $\begin{array}{l}413 \\
(34.47)\end{array}$ & $\begin{array}{l}8566 \\
(38.42)\end{array}$ & \\
\hline $\begin{array}{l}\text { Senior high school } \\
\text { or above }\end{array}$ & $\begin{array}{l}4407 \\
(18.75)\end{array}$ & $\begin{array}{l}179 \\
(13.56)\end{array}$ & $\begin{array}{l}4228 \\
(19.07)\end{array}$ & & $\begin{array}{l}150 \\
(12.52)\end{array}$ & $\begin{array}{l}4257 \\
(19.09)\end{array}$ & \\
\hline $\begin{array}{l}\text { Married/cohabiting } \\
\mathrm{n}(\%)\end{array}$ & $\begin{array}{l}21195 \\
(90.21)\end{array}$ & $\begin{array}{l}1157 \\
(87.65)\end{array}$ & $\begin{array}{l}20038 \\
(90.36)\end{array}$ & 0.002 & $\begin{array}{l}1053 \\
(87.90)\end{array}$ & $\begin{array}{l}20142 \\
(90.33)\end{array}$ & 0.006 \\
\hline \multicolumn{8}{|l|}{$\begin{array}{l}\text { Average monthly } \\
\text { income } \mathrm{n}(\%)\end{array}$} \\
\hline$<500 \mathrm{RMB}$ & $\begin{array}{l}8680 \\
(36.94)\end{array}$ & $\begin{array}{l}657 \\
(49.77)\end{array}$ & $\begin{array}{l}8023 \\
(36.18)\end{array}$ & $<.001$ & $\begin{array}{l}551 \\
(45.99)\end{array}$ & $\begin{array}{l}8129 \\
(36.46)\end{array}$ & $<.001$ \\
\hline 500- RMB & $\begin{array}{l}7452 \\
(31.72)\end{array}$ & $\begin{array}{l}325 \\
(24.62)\end{array}$ & $\begin{array}{l}7127 \\
(32.14)\end{array}$ & & $\begin{array}{l}314 \\
(26.21)\end{array}$ & $\begin{array}{l}7138 \\
(32.01)\end{array}$ & \\
\hline$\geq 1000 \mathrm{RMB}$ & $\begin{array}{l}7364 \\
(31.34)\end{array}$ & $\begin{array}{l}338 \\
(25.61)\end{array}$ & $\begin{array}{l}7026 \\
(31.68)\end{array}$ & & $\begin{array}{l}333 \\
(27.80)\end{array}$ & $\begin{array}{l}7031 \\
(31.53)\end{array}$ & \\
\hline \multicolumn{8}{|l|}{$\begin{array}{l}\text { Physical activity } n \\
\text { (\%) }\end{array}$} \\
\hline Low & $\begin{array}{l}8113 \\
(34.53)\end{array}$ & $\begin{array}{l}484 \\
(36.67)\end{array}$ & $\begin{array}{l}7629 \\
(34.40)\end{array}$ & 0.215 & $\begin{array}{l}365 \\
(30.47)\end{array}$ & $\begin{array}{l}7748 \\
(34.75)\end{array}$ & 0.009 \\
\hline Moderate & $\begin{array}{l}7819 \\
(33.28)\end{array}$ & $\begin{array}{l}432 \\
(32.73)\end{array}$ & $\begin{array}{l}7387 \\
(33.31)\end{array}$ & & $\begin{array}{l}430 \\
(35.89)\end{array}$ & $\begin{array}{l}7389 \\
(33.14)\end{array}$ & \\
\hline High & $\begin{array}{l}7564 \\
(32.19)\end{array}$ & $\begin{array}{l}404 \\
(30.60)\end{array}$ & $\begin{array}{l}7160 \\
(32.29)\end{array}$ & & $\begin{array}{l}403 \\
(33.64)\end{array}$ & $\begin{array}{l}7161 \\
(32.11)\end{array}$ & \\
\hline
\end{tabular}

*Chronic diseases including hypertension, dyslipidemia, T2DM, CHD and stroke.

Abbreviation: SD, standard deviation; RMB, Renminbi; BMI, Body mass index. 


\begin{tabular}{|c|c|c|c|c|c|c|c|}
\hline \multirow[t]{2}{*}{ Variable } & \multirow{2}{*}{$\begin{array}{l}\text { Total } \\
(n= \\
23496)\end{array}$} & \multicolumn{2}{|c|}{ Depressive symptoms } & \multirow[t]{2}{*}{$P$} & \multicolumn{2}{|c|}{ Anxiety disorder } & \multirow[t]{2}{*}{$P$} \\
\hline & & $\begin{array}{l}\text { Depressive } \\
(n=1320)\end{array}$ & $\begin{array}{l}\text { Non- } \\
\text { depressive } \\
(n=22176)\end{array}$ & & $\begin{array}{l}\text { Anxiety } \\
(\mathrm{n}= \\
1198)\end{array}$ & $\begin{array}{l}\text { Non- } \\
\text { anxiety } \\
(n= \\
22298)\end{array}$ & \\
\hline $\begin{array}{l}\text { Current smoking } n \\
(\%)\end{array}$ & $\begin{array}{l}4707 \\
(20.03)\end{array}$ & $\begin{array}{l}211 \\
(15.98)\end{array}$ & $\begin{array}{l}4496 \\
(20.27)\end{array}$ & $\begin{array}{l}< \\
0.001\end{array}$ & $\begin{array}{l}174 \\
(14.52)\end{array}$ & $\begin{array}{l}4533 \\
(20.33)\end{array}$ & $\begin{array}{l}< \\
0.001\end{array}$ \\
\hline $\begin{array}{l}\text { Current drinking } n \\
(\%)\end{array}$ & $\begin{array}{l}4257 \\
(18.12)\end{array}$ & $\begin{array}{l}173 \\
(13.11)\end{array}$ & $\begin{array}{l}4084 \\
(18.42)\end{array}$ & $\begin{array}{l}< \\
0.001\end{array}$ & $\begin{array}{l}146 \\
(12.19)\end{array}$ & $\begin{array}{l}4111 \\
(18.44)\end{array}$ & $\begin{array}{l}<.001 \\
0.001\end{array}$ \\
\hline $\begin{array}{l}\text { Chronic disease }{ }^{\star} \mathrm{n} \\
(\%)\end{array}$ & $\begin{array}{l}14578 \\
(62.04)\end{array}$ & $\begin{array}{l}844 \\
(63.94)\end{array}$ & $\begin{array}{l}13734 \\
(61.93)\end{array}$ & 0.153 & $\begin{array}{l}740 \\
(61.77)\end{array}$ & $\begin{array}{l}13838 \\
(62.06)\end{array}$ & 0.855 \\
\hline $\begin{array}{l}\mathrm{BMI}(\mathrm{kg} / \mathrm{m} 2 \text {, mean } \\
\pm \mathrm{SD})\end{array}$ & $\begin{array}{l}24.99 \\
\pm 3.60\end{array}$ & $\begin{array}{l}24.67 \pm \\
3.80\end{array}$ & $25.00 \pm 3.59$ & 0.002 & $\begin{array}{l}24.59 \\
\pm 3.59\end{array}$ & $\begin{array}{l}25.01 \pm \\
3.60\end{array}$ & $\begin{array}{l}<.001 \\
0.001\end{array}$ \\
\hline $\begin{array}{l}\text { Utility index (mean } \\
\pm \text { SD) }\end{array}$ & $\begin{array}{l}0.954 \\
\pm 0.111\end{array}$ & $\begin{array}{l}0.829 \pm \\
0.224\end{array}$ & $\begin{array}{l}0.962 \pm \\
0.095\end{array}$ & $\begin{array}{l}< \\
0.001\end{array}$ & $\begin{array}{l}0.835 \\
\pm 0.222\end{array}$ & $\begin{array}{l}0.961 \pm \\
0.097\end{array}$ & $\begin{array}{l}<.001 \\
0.001\end{array}$ \\
\hline $\begin{array}{l}\text { VAS scores (mean } \\
\pm \text { SD) }\end{array}$ & $\begin{array}{l}78.33 \\
\pm 14.80\end{array}$ & $\begin{array}{l}66.71 \pm \\
18.27\end{array}$ & $\begin{array}{l}79.04 \pm \\
14.25\end{array}$ & $<.001$ & $\begin{array}{l}67.43 \\
\pm 18.10\end{array}$ & $\begin{array}{l}78.94 \pm \\
14.34\end{array}$ & $\begin{array}{l}<.001 \\
0.001\end{array}$ \\
\hline \multicolumn{8}{|c|}{ *Chronic diseases including hypertension, dyslipidemia, T2DM, CHD and stroke. } \\
\hline
\end{tabular}

\section{Self-reported health problems of EQ-5D-5L}

Figure 1 demonstrated the self-reported health problems of EQ-5D-5L in total sample, depressive group, and anxiety group. Of all participants, the most frequently reported problem was pain/discomfort dimension (23.03\%), followed by mobility (12.72\%), anxiety/depression (7.76\%), usual activities (6.44\%), while the least report was the self-care dimension (3.66\%). In depressive group and anxiety group, the most frequently reported problem was still reported in pain/discomfort dimension (52.43\% and $51.75 \%$, respectively), followed by anxiety/depression ( $42.41 \%$ and $41.13 \%$, respectively). In both the depressive group and the anxiety group, the percentage of problems reported on all five dimensions increased significantly, especially in anxiety/depression and pain/discomfort dimension. Compared with nondepressive group and non-anxiety group, depressive group and anxiety group had higher percentage of reported health problems in all of five dimensions (all $P<0.001$ ).

\section{Associations between depressive symptoms, anxiety disorders and HRQOL}

The results of Tobit regression and Generalized linear models analyses on utility index and VAS score were summarized in Table 2. After multiple adjustments, the Tobit regression model and GLM indicated that both utility index and VAS score were lower in participants with depressive symptoms or anxiety 
disorders. The regression coefficients and $95 \%$ confidence interval $(\mathrm{Cl})$ of utility index for depressive symptoms and anxiety disorders were $-0.166(-0.182,-0.149)$ and $-0.132(-0.149,-0.114)$, respectively. The regression coefficients and $95 \% \mathrm{Cl}$ of VAS score for depressive symptoms and anxiety disorders were $-7.65(-8.60,-6.70)$ and $-5.79(-6.78,-4.80)$, respectively. In addition, the regression coefficients and $95 \%$ $\mathrm{Cl}$ of utility index associated with 1 score increase in PHQ-2 score and GAD-2 score were $-0.040(-0.044$, $-0.036)$ and $-0.034(-0.039,-0.030)$, respectively. The regression coefficients and $95 \% \mathrm{Cl}$ of VAS score associated with 1 score increase in PHQ-2 score and GAD-2 score were $-2.25(-2.48,-2.03)$ and -1.27 $(-1.50,-1.04)$.

Table 2

The results of Tobit regression and Generalized linear models analyses on utility index and VAS score.
Model $1(\beta(95 \% \mathrm{Cl}))$
Model 2 ( $\beta(95 \% \mathrm{Cl}))$
Model $2(\beta(95 \% \mathrm{Cl}))$

Utility index VAS score Utility index VAS score Utility index VAS score

\section{Depressive \\ symptoms}

$\begin{array}{lllllll}\text { PHQ-2 score } & -0.045 & -2.45 & -0.042 & -2.38 & -0.040 & -2.25 \\ & (-0.050, & (-2.68, & (-0.046, & (-2.61, & (-0.044, & (-2.48, \\ & -0.041) & -2.21) & -0.038) & -2.15) & -0.036) & -2.03) \\ \text { Yes } & -0.194 & -9.03 & -0.174 & -8.22 & -0.166 & -7.65 \\ & (-0.212, & (-10.01, & (-0.191, & (-9.18, & (-0.182, & (-8.60, \\ & -0.176) & -8.04) & -0.167) & -7.26) & -0.149) & -6.70) \\ \text { No } & \text { Reference } & \text { Reference } & \text { Reference } & \text { Reference } & \text { Reference } & \text { Reference }\end{array}$

\section{Anxiety}

disorders

$\begin{array}{lllllll}\text { GAD-2 score } & -0.035 & -1.24 & -0.035 & -1.33 & -0.034 & -1.27 \\ & (-0.039, & (-1.48, & (-0.039, & (-1.56, & (-0.039, & (-1.50, \\ & -0.030) & -0.99) & -0.031)^{\prime} & -1.09)^{\prime} & -0.030) & -1.04)^{\prime} \\ \text { Yes } & -0.139 & -6.03 & -0.135 & -6.05 & -0.132 & -5.79 \\ & (-0.158, & (-7.06, & (-0.153, & (-7.05, & (-0.149, & (-6.78, \\ & -0.121) & -4.99) & -0.117) & -5.05) & -0.114) & -4.80) \\ \text { No } & \text { Reference } & \text { Reference } & \text { Reference } & \text { Reference } & \text { Reference } & \text { Reference }\end{array}$

Abbreviation: Cl, confidence interval; PHQ-2, Patient Health Questionnaire-2; GAD-2, Generalized Anxiety Disorder-2.

Model 1: Unadjusted.

Model 2: Adjusted age, gender, marital status, education level, average monthly income, physical activity, smoking status, drinking status, and BMI.

Model 3: Adjusted hypertension, dyslipidemia, T2DM, CHD and stroke based on model 2. 
Figure 2 presented the gender specific associations between depressive symptoms, anxiety disorders and utility index and VAS score. Both in men and women, the significantly negative associations between depressive, anxiety disorders and utility index and VAS score was observed. Additionally, there was no interaction between depressive symptoms, anxiety disorders and gender (all $P_{\text {for interaction }}>0.05$ ).

\section{Associations between comorbidity and utility index and VAS score.}

The gender specific associations between comorbidity and utility index and VAS score were showed in Fig. 3. The findings indicated that comorbidity was strongest associated with low utility index and VAS score. Of total sample, the regression coefficients and $95 \% \mathrm{Cl}$ for comorbidity in utility index and VAS score were $-0.288(-0.305,-0.271)$ and $-13.61(-14.61,-12.60)$, respectively. Notably, the negative associations between depressive symptoms and HRQoL was stronger than anxiety disorders. These findings were observed robustly in men and women.

\section{Discussion}

In this large population-based study, we investigated the association between depressive symptoms, anxiety disorders, their comorbidity and HRQoL, and assessed the difference between men and women. The mean (SD) utility index and VAS score of the total sample were 0.954 (0.111) and 78.33 (14.80), respectively. Of all participants, the most frequently reported problem was pain/discomfort dimension, while the least report was the self-care dimension. In both the depressive group and the anxiety group, the percentage of problems reported on all five dimensions increased significantly, especially in anxiety/depression and pain/discomfort dimension. In addition, our results suggested that comorbidity was strongest associated with low HRQoL. Notably, the negative associations between depressive symptoms and HRQoL was stronger than anxiety disorders. These findings were observed robustly in men and women.

Participants in previous studies conducted in medical institutions had low utility index and VAS score [28, 29]. However, most participants in this study were satisfactory with their HRQoL, which was consistence with the previous studies conducted in China $[10,30]$. It may be due to the participants of this study were recruited from rural areas and lived a normal life at home, which hinted HRQoL is better than those who live in medical institutions for professional care. Of all participants, the most frequently reported problem was reported in pain/discomfort dimension, while the least report was the self-care dimension. This was in line with previous studies in China $[9,10]$. In both the depressive group and the anxiety group, the percentage of problems reported on all five dimensions increased significantly, especially in anxiety/depression and pain/discomfort dimension. Depressive symptoms and anxiety disorders increased the self-reported problems in pain/discomfort dimension, it may be due to mental disorders and chronic pain tend to further aggravate the severity of both disorders [31]. Self-reported problems in anxiety/depression dimension increased in depressive group and the anxiety group, which indicated that 
subjectively perceived depression and anxiety were similar to those detected by the PHQ-2 and GAD-2 scale.

In this study, depressive symptoms and anxiety disorders were associated with low HRQoL. Previous study conducted in specific population with chronic diseases have found stable associations between mental disorders and low HRQoL [12-14, 32]. In addition, serval studies conducted in old adults also found the negative associations between mental disorders and HRQoL [33-36]. The negative association between depression and HRQoL was also observed in postmenopausal women in Korea [37]. The findings of these studies were consistent with the current study. However, these studies were all conducted in specific subgroup of population, and may not fully reflect the association between mental health and HRQoL. The current study conducted in general rural population contributed new evidence in rural area and may provide a better understanding of the mental determinants of improving the HRQoL. Nonetheless, it should be noted that our findings based on cross-sectional study cannot confirm causal relationship between depressive symptoms, anxiety disorders and HRQoL. Certainly, a study suggested that low HRQoL was associated with depression [38].

To the best of our knowledge, this is the first study to investigate the association between comorbidity and HRQoL, whcih suggested that comorbidity was strongest associated with low HRQoL. A prior study conducted in Swedish general population found that comorbidity was associated with higher symptom severity and lower health-related quality of life [39]. However, this study only explored the relationship between comorbidity and each dimension of EQ-5D. The current study has explored the association between comorbidity and utility index calculated according to the recently available Chinese value set, which can better reflect the HRQoL. Our study also found that the negative associations between depressive symptoms and HRQoL was stronger than anxiety disorders. However, we have not found any other research evidence to support our results and it need further exploration.

There were several limitations in this study. Firstly, the results only can indicate association and cannot establish causal relationship, because this study was cross-sectional design. Prospective studies on mental disorders and HRQoL are needed. Secondly, the PHQ-2 and GAD-2 are useful screening measures rather than diagnostic tools, thus the prevalence of depressive symptoms and anxiety disorders may be overestimate, which can induce bias. However, in busy primary care or large population studies, these two scales were quite suitable for saving time while still providing accepted diagnostic performances. Thirdly, some information of participants in this study was collected based on self-reported, but higher test-retest reliability, effective training of study workers and good field implementation will ensure the accuracy and reliability of the information.

\section{Conclusions}

In summary, this study demonstrated that depressive symptoms and anxiety disorders were negatively associated with HRQoL. In addition, comorbidity was strongest associated with low HRQoL and the negative associations between depressive symptoms and HRQoL was stronger than anxiety disorders. 
These findings were observed robustly in men and women. However, large-scale prospective studies are needed to prove our findings and provide more information about the causal relationship and internal mechanisms of this association.

\section{List Of Abbreviations}

T2DM, type 2 diabetes mellitus; CHD, coronary heart disease; HRQoL, health related quality of life; IPAQ, International Physical Activity Questionnaire; BMI, body mass index; PHQ-2, Patient Health Questionnaire2; GAD-2, Generalized Anxiety Disorder-2; PHQ-9, Patient Health Questionnaire-9; GAD-7, seven-item generalized anxiety disorder scale; EQ-5D-5L, European Quality of Life Five Dimension Five Level Scale; MO, mobility; SC, self-care; UA, usual activities; PD, pain/discomfort; AD, anxiety/depression; VAS, visual analogue scale; SD, standard deviations; GLM, generalized linear model.

\section{Declarations}

\section{Ethics approval and consent to participate}

Ethics approval was obtained from the "Zhengzhou University Life Science Ethics Committee", and written informed consent was obtained for all participants. Ethics approval code: [2015] MEC (S128). The study is conducted in accordance with the principles of the Declaration of Helsinki

\section{Consent for Publication}

Not applicable.

\section{Availability of data and material}

The data analyzed during current study are available from the corresponding author on reasonable request.

\section{Competing interests}

The authors declare that they have no competing interests.

\section{Funding}

This research was supported by the Foundation of National Key Program of Research and Development of China (Grant NO: 2016YFC0900803), The Science and Technology Innovation Team Support Plan of Colleges and Universities in Henan Province (Grant NO:21IRTSTHN029), Foundation of Medical Science and Technology of Henan province (Grant NO: 201702367, 2017T02098), Discipline Key Research and Development Program of Zhengzhou University (Grant NO: XKZDQY202008, XKZDQY202002). The funders did not influence any stage of this study.

\section{Authors' contributions}


CW and FW conceived and designed the study. WL, ZL, XD, XW and YM analyzed the data. WL, YL, NC, $\mathrm{NK}, \mathrm{XL}$ and $\mathrm{WH}$ drafted the manuscript. $\mathrm{ZL}, \mathrm{XD}, \mathrm{XW}, \mathrm{YM}, \mathrm{YL}$ and $\mathrm{CW}$ collected data. $\mathrm{XL}, \mathrm{WH}, \mathrm{FW}$, and $\mathrm{CW}$ provided technical direction and writing assistance in the preparation of this manuscript. All authors critically revised the manuscript and approved the final version for publication.

\section{Acknowledgments}

The authors thank all the participants, coordinators, and administrators for their support and help during the research. In addition, the authors would like to thank Dr. Tanko Abdulai for his critical reading of the manuscript.

\section{References}

1. Hock RS, Or F, Kolappa K, Burkey MD, Surkan PJ, Eaton WW. A new resolution for global mental health. Lancet. 2012; 379(9824):1367-8. https://doi.org/10.1016/s0140-6736(12)60243-8.

2. Phillips MR, Zhang J, Shi Q, Song Z, Ding Z, Pang S, et al. Prevalence, treatment, and associated disability of mental disorders in four provinces in China during 2001-05: an epidemiological survey. Lancet. 2009; 373(9680):2041-53. https://doi.org/10.1016/s0140-6736(09)60660-7.

3. Zbozinek TD, Rose RD, Wolitzky-Taylor KB, Sherbourne C, Sullivan G, Stein MB, et al. Diagnostic overlap of generalized anxiety disorder and major depressive disorder in a primary care sample. Depress Anxiety. 2012; 29(12):1065-71. https://doi.org/10.1002/da.22026.

4. Luo Z, Li Y, Hou Y, Liu X, Jiang J, Wang Y, et al. Gender-specific prevalence and associated factors of major depressive disorder and generalized anxiety disorder in a Chinese rural population: the Henan rural cohort study. BMC Public Health. 2019; 19(1):1744. https://doi.org/10.1186/s12889-019-80861.

5. Johnson HM. Anxiety and Hypertension: Is There a Link? A Literature Review of the Comorbidity Relationship Between Anxiety and Hypertension. Curr Hypertens Rep. 2019; 21(9):66. https://doi.org/10.1007/s11906-019-0972-5.

6. Graham EA, Deschênes SS, Khalil MN, Danna S, Filion KB, Schmitz N. Measures of depression and risk of type 2 diabetes: A systematic review and meta-analysis. J Affect Disord. 2020; 265:224-232. https://doi.org/10.1016/j.jad.2020.01.053.

7. Peter RS, Meyer ML, Mons U, Schöttker B, Keller F, Schmucker R, et al. Long-term trajectories of anxiety and depression in patients with stable coronary heart disease and risk of subsequent cardiovascular events. Depress Anxiety. 2020; 37(8):784-792. https://doi.org/10.1002/da.23011.

8. Karimi M, Brazier J. Health, Health-Related Quality of Life, and Quality of Life: What is the Difference? Pharmacoeconomics. 2016; 34(7):645-9. https://doi.org/10.1007/s40273-016-0389-9.

9. Wu H, Li H, Li H, Ding Y, Wang C, Zhang G, et al. Evaluation of health-related quality of life in adults with and without dyslipidaemia in rural areas of central China. Qual Life Res. 2020; 29(4):925-939. https://doi.org/10.1007/s11136-019-02336-0. 
10. Liang Z, Zhang T, Lin T, Liu L, Wang B, Fu AZ, et al. Health-related quality of life among rural men and women with hypertension: assessment by the EQ-5D-5L in Jiangsu, China. Qual Life Res. 2019; 28(8):2069-2080. https://doi.org/10.1007/s11136-019-02139-3.

11. Khunkaew S, Fernandez R, Sim J. Demographic and clinical predictors of health-related quality of life among people with type 2 diabetes mellitus living in northern Thailand: A cross-sectional study. Health Qual Life Outcomes. 2019; 17(1):177. https://doi.org/10.1186/s12955-019-1246-2.

12. Liu X, Haagsma J, Sijbrands E, Buijks H, Boogaard L, Mackenbach JP, et al. Anxiety and depression in diabetes care: longitudinal associations with health-related quality of life. Sci Rep. 2020; 10(1):8307. https://doi.org/10.1038/s41598-020-57647-x.

13. Sullivan MD, Newton K, Hecht J, Russo JE, Spertus JA. Depression and health status in elderly patients with heart failure: a 6-month prospective study in primary care. Am J Geriatr Cardiol. 2004; 13(5):252-60. https://doi.org/10.1111/j.1076-7460.2004.03072.x.

14. Fu T, Cao H, Yin R, Zhang L, Zhang Q, Li L, et al. Depression and anxiety correlate with disease-related characteristics and quality of life in Chinese patients with gout: a case-control study. Psychol Health Med. 2018; 23(4):400-410. https://doi.org/10.1080/13548506.2017.1378819.

15. Salk RH, Hyde JS, Abramson LY. Gender differences in depression in representative national samples: Meta-analyses of diagnoses and symptoms. Psychol Bull. 2017; 143(8):783-822. https://doi.org/10.1037/bul0000102.

16. Asher M, Asnaani A, Aderka IM. Gender differences in social anxiety disorder: A review. Clin Psychol Rev. 2017; 56:1-12. https://doi.org/10.1002/jclp.22624.

17. Liu X, Mao Z, Li Y, Wu W, Zhang X, Huo W, et al. Cohort Profile: The Henan Rural Cohort: a prospective study of chronic non-communicable diseases. Int J Epidemiol. 2019; 48(6):1756-1756j. https://doi.org/10.1093/ije/dyz039.

18. Li R, Tian Z, Wang Y, Liu X, Tu R, Wang Y, et al. The Association of Body Fat Percentage With Hypertension in a Chinese Rural Population: The Henan Rural Cohort Study. Front Public Health. 2020; 8:70. https://doi.org/10.3389/fpubh.2020.00070.

19. Macfarlane D, Chan A, Cerin E. Examining the validity and reliability of the Chinese version of the International Physical Activity Questionnaire, long form (IPAQ-LC). Public Health Nutr. 2011; 14(3):443-50. https://doi.org/10.1017/s1368980010002806.

20. Wang Y, Li Y, Liu X, Zhang H, Abdulai T, Tu R, et al. Prevalence and Influencing Factors of Coronary Heart Disease and Stroke in Chinese Rural Adults: The Henan Rural Cohort Study. Front Public Health. 2020; 7:411. https://doi.org/10.3389/fpubh.2019.00411.

21. Liu ZW, Yu Y, Hu M, Liu HM, Zhou L, Xiao SY. PHQ-9 and PHQ-2 for Screening Depression in Chinese Rural Elderly. PLoS One. 2016; 11(3):e0151042. https://doi.org/10.1371/journal.pone.0151042.

22. Luo Z, Li Y, Hou Y, Zhang H, Liu X, Qian X,et al. Adaptation of the two-item generalized anxiety disorder scale (GAD-2) to Chinese rural population: A validation study and meta-analysis. Gen Hosp Psychiatry. 2019; 60:50-56. https://doi.org/10.1016/j.genhosppsych.2019.07.008. 
23. Yu X, Stewart SM, Wong PT, Lam TH. Screening for depression with the Patient Health Questionnaire2 (PHQ-2) among the general population in Hong Kong. J Affect Disord. 2011; 134(1-3):444-7. https://doi.org/10.1016/j.jad.2011.05.007.

24. Rabin R, de Charro F. EQ-5D: a measure of health status from the EuroQol Group. Ann Med. 2001; 33(5):337-43. https://doi.org/10.3109/07853890109002087.

25. Luo N, Liu G, Li M, Guan H, Jin X, Rand-Hendriksen K. Estimating an EQ-5D-5L Value Set for China. Value Health. 2017; 20(4):662-669. https://doi.org/10.1016/j.jval.2016.11.016

26. Kang N, Liu X, Liao W, Tu R, Sang S, Zhai Z, et al. Health-related quality of life among rural adults with type 2 diabetes mellitus: a cross-sectional study. Eur J Public Health. 2021: ckaa247. https://doi.org/10.1093/eurpub/ckaa247.

27. Austin PC. Bayesian extensions of the Tobit model for analyzing measures of health status. Med Decis Making. 2002; 22(2):152-62. https://doi.org/10.1177/0272989x0202200212.

28. Arifin B, Idrus LR, van Asselt ADI, Purba FD, Perwitasari DA, Thobari JA, et al. Health-related quality of life in Indonesian type 2 diabetes mellitus outpatients measured with the Bahasa version of EQ-5D. Qual Life Res. 2019; 28(5):1179-1190. https://doi.org/10.1007/s11136-019-02105-z.

29. Tušek-Bunc K, Petek D. Comorbidities and characteristics of coronary heart disease patients: their impact on health-related quality of life. Health Qual Life Outcomes. 2016; 14(1):159. https://doi.org/10.1186/s12955-016-0560-1.

30. Bao XY, Xie YX, Zhang XX, Peng X, Huang JX, Du QF, et al. The association between multimorbidity and health-related quality of life: a cross-sectional survey among community middle-aged and elderly residents in southern China. Health Qual Life Outcomes. 2019; 17(1):107. https://doi.org/10.1186/s12955-019-1175-0.

31. Sheng J, Liu S, Wang Y, Cui R, Zhang X. The Link between Depression and Chronic Pain: Neural Mechanisms in the Brain. Neural Plast. 2017; 9724371. https://doi.org/10.1155/2017/9724371.

32. Akioyamen LE, Genest J, Shan SD, Inibhunu H, Chu A, Tu JV. Anxiety, depression, and health-related quality of life in heterozygous familial hypercholesterolemia: A systematic review and meta-analysis. J Psychosom Res. 2018; 109:32-43. https://doi.org/10.1016/j.jpsychores.2018.03.170.

33. Sivertsen H, Bjørkløf GH, Engedal K, Selbæk G, Helvik AS. Depression and Quality of Life in Older Persons: A Review. Dement Geriatr Cogn Disord. 2015; 40(5-6):311-39. https://doi.org/10.1159/000437299.

34. Van der Weele GM, Gussekloo J, De Waal MW, De Craen AJ, Van der Mast RC. Co-occurrence of depression and anxiety in elderly subjects aged 90 years and its relationship with functional status, quality of life and mortality. Int J Geriatr Psychiatry. 2009; 24(6):595-601. https://doi.org/10.1002/gps.2162.

35. Hajek A, Brettschneider C, Ernst A, Lange C, Wiese B, Prokein J, et al. Complex coevolution of depression and health-related quality of life in old age. Qual Life Res. 2015; 24(11):2713-22. https://doi.org/10.1007/s11136-015-1005-8. 
36. Han K, Yang S, Jia W, Wang S, Song Y, Cao W, et al. Health-Related Quality of Life and Its Correlation With Depression Among Chinese Centenarians. Front Public Health. 2020; 8:580757. https://doi.org/10.3389/fpubh.2020.580757.

37. Park H, Kim K. Depression and Its Association with Health-Related Quality of Life in Postmenopausal Women in Korea. Int J Environ Res Public Health. 2018; 15(11):2327. https://doi.org/10.3390/ijerph15112327.

38. Jang J, Jung HS, Wang J, Kim S. Effects of Health-Related Quality of Life on Suicidal Ideation and Depression among Older Korean Adults: A Cross-Sectional Study. Psychiatry Investig. 2021; 18(1):3138. https://doi.org/10.30773/pi.2020.0159.

39. Johansson R, Carlbring P, Heedman Å, Paxling B, Andersson G. Depression, anxiety and their comorbidity in the Swedish general population: point prevalence and the effect on health-related quality of life. PeerJ. 2013; 1:e98. https://doi.org/10.7717/peerj.98.

\section{Figures}



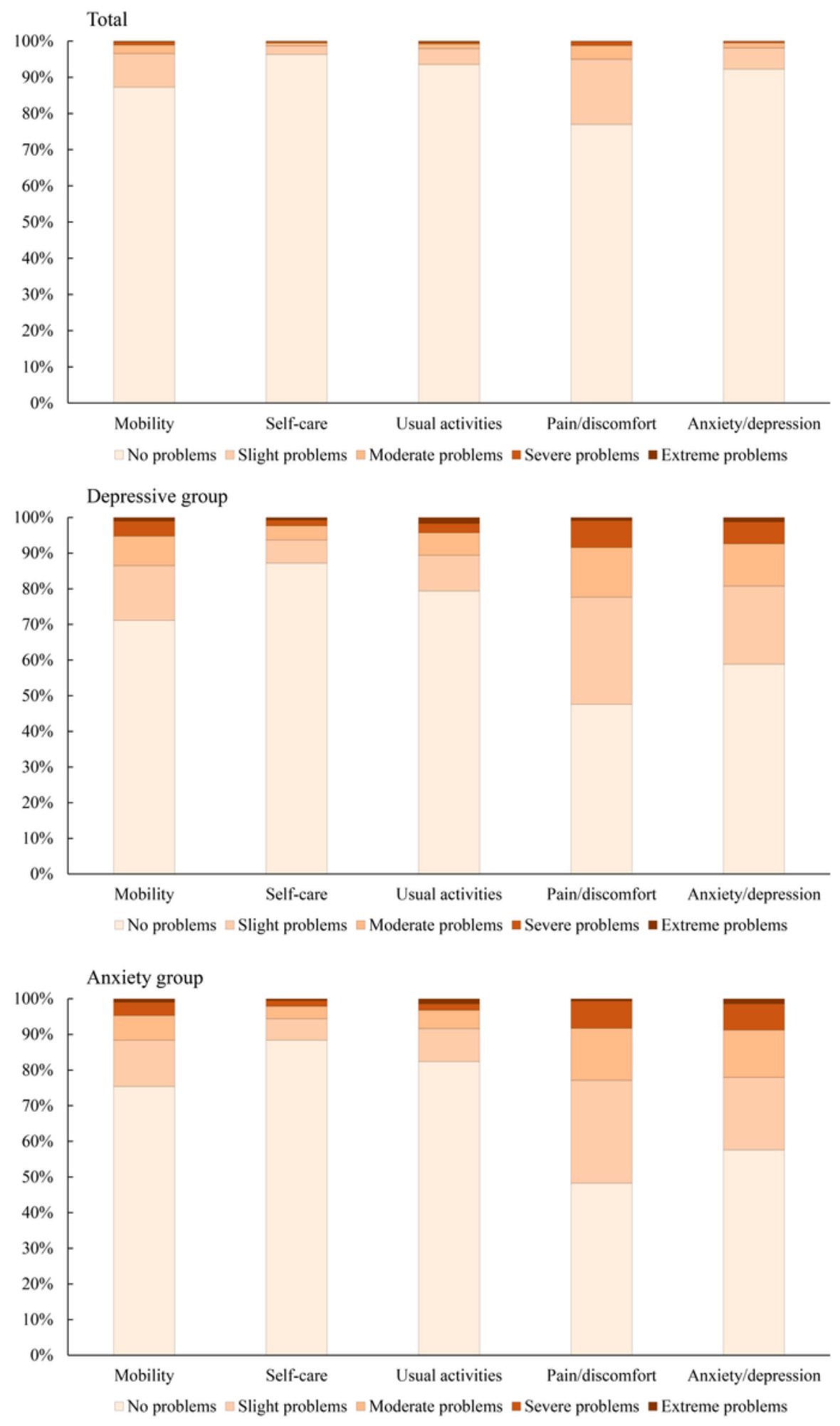

\section{Figure 1}

Self-reported health problems of EQ-5D-5L in total sample, depressive group, and anxiety group. 


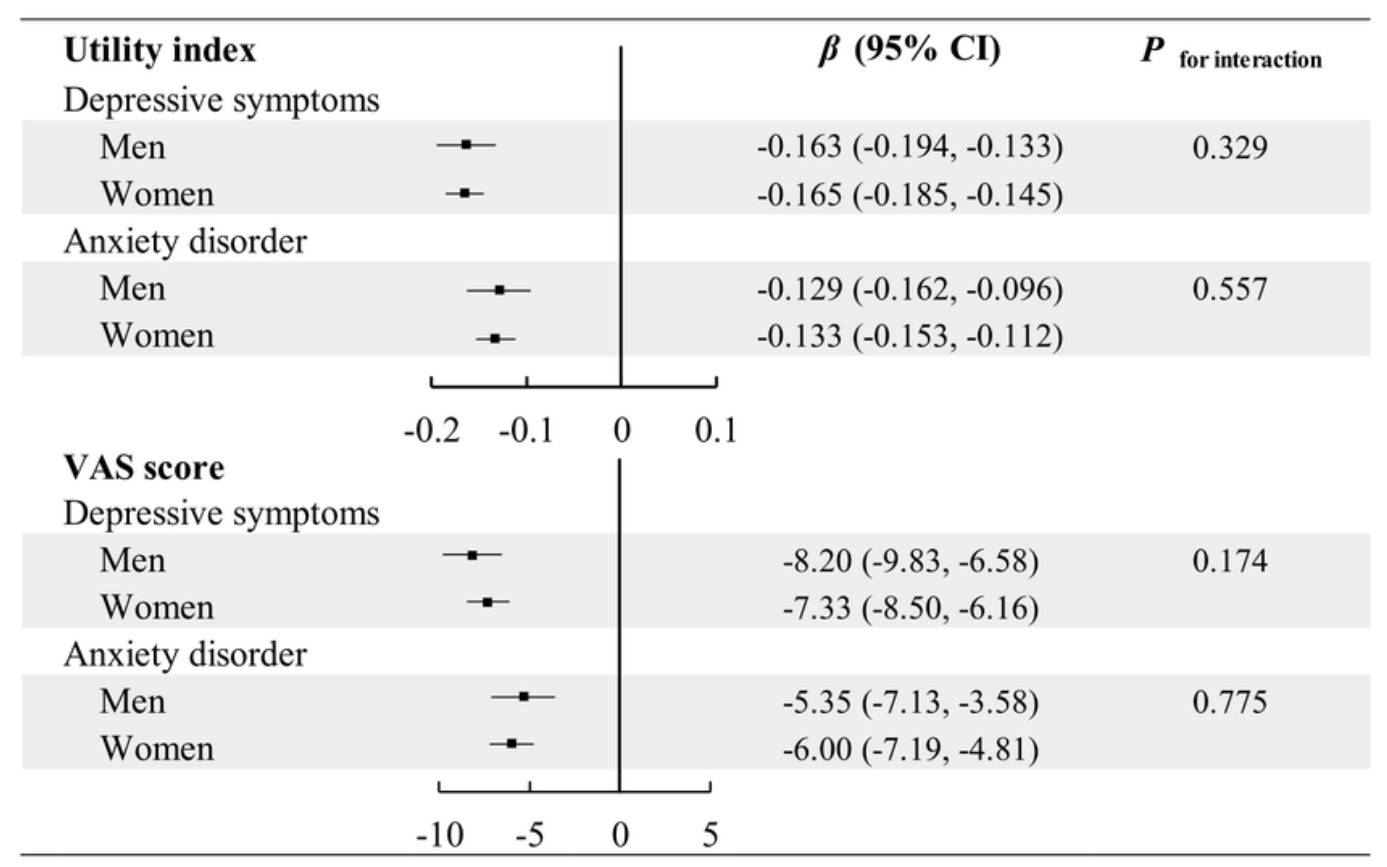

\section{Figure 2}

Gender specific associations between depressive symptoms, anxiety disorders and utility index and VAS score (Adjusted age, gender, marital status, education level, average monthly income, physical activity, smoking status, drinking status, BMI, hypertension, dyslipidemia, T2DM, CHD and stroke). 


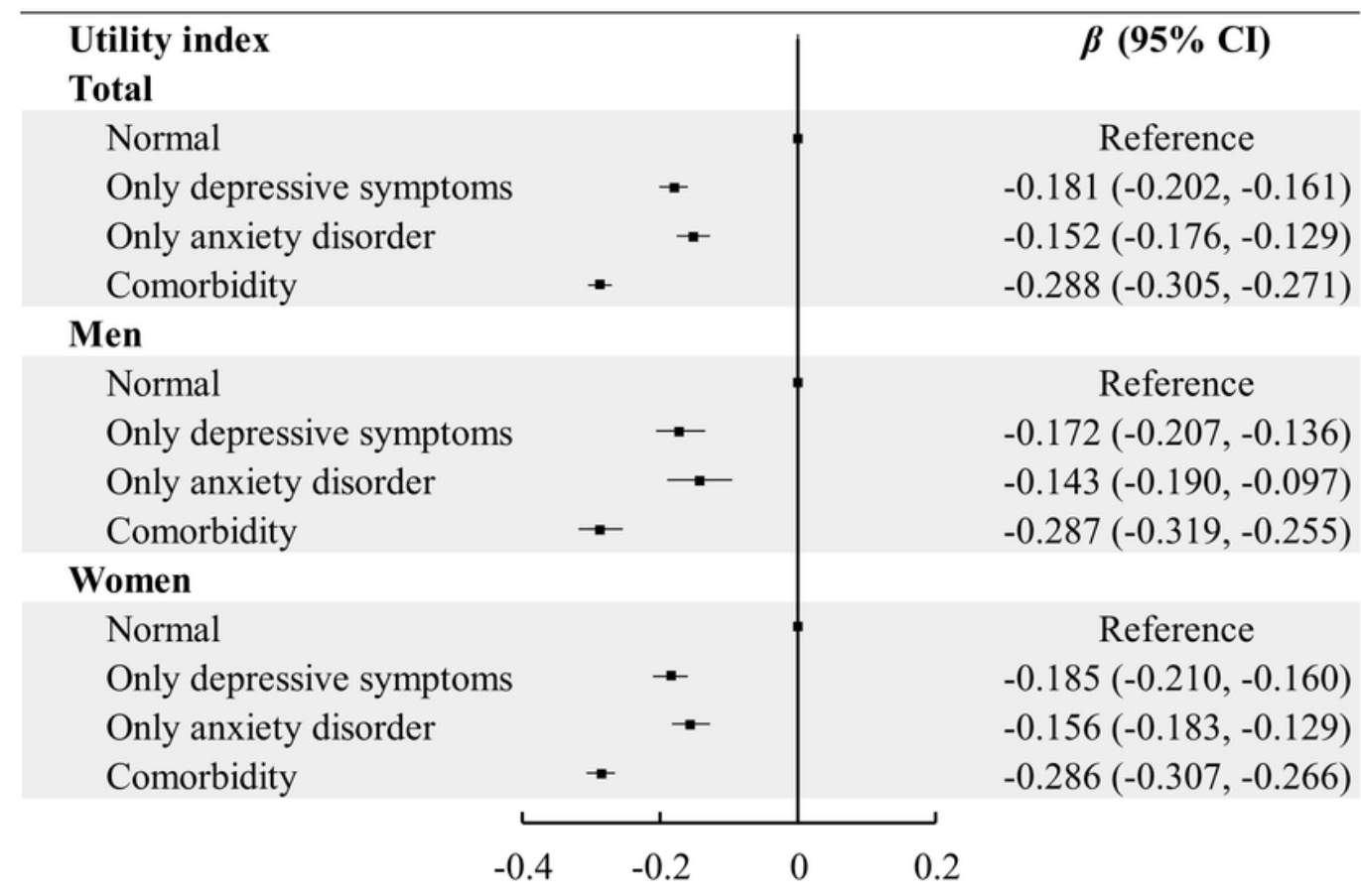

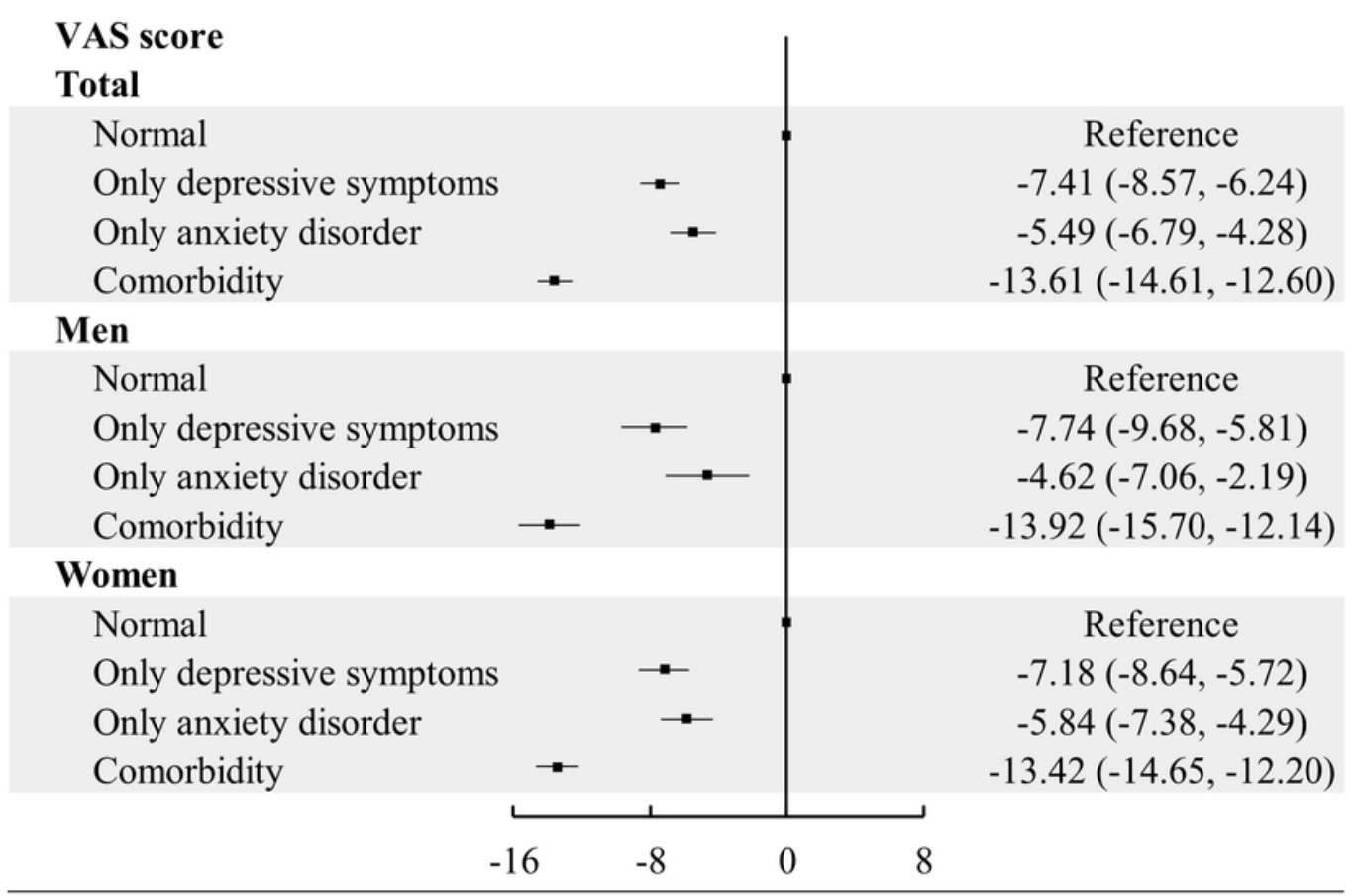

\section{Figure 3}

Gender specific associations between comorbidity and utility index and VAS score (Adjusted age, gender, marital status, education level, average monthly income, physical activity, smoking status, drinking status, BMI, hypertension, dyslipidemia, T2DM, CHD and stroke). 